\title{
Effect of Educational Program on Nurses' Knowledge and Practice About Oxygen Therapy
}

\author{
Asmaa Hamdy Mostafa ${ }^{1}$, Moggeda Mohamed Mehany ${ }^{2}$ \& Mona Abd Elaziem Ahmed ${ }^{3}$. \\ 1. Nurse Specialist at Assuit Pediatric University Hospital, Egypt \\ 2. Assistant Prof. of critical care and emergency department, Faculty of Nursing, Assuit University, Egypt . \\ 3. Lecturer of critical care and emergency department, Faculty of Nursing, Assuit University, Egypt.
}

\begin{abstract}
Oxygen is life essential so it is important for nurses who are responsible for oxygen administration to be familiar with its Indications and potential hazards. Aim: To investigate the effect of educational program about oxygen therapy on the nurses' knowledge and nurses' practice. Design: A Quasi experimental research design was used. Setting: The study was carried in pediatric emergency unit at Assuit pediatric University Hospital. Subjects: All available nurses in the emergency department who were (50) nurses. Tools: Two tools were utilized, Tool (1): Structure Interview Questionnaire to assess nurses' knowledge, Tool (2): Nurses' practice observational check list to assess performance. Method: preparatory, implementation and evaluation phases were used to implement study. Results: The total nurses' knowledge mean score improved from $(9.080 \pm 4.818)$ before educational program to

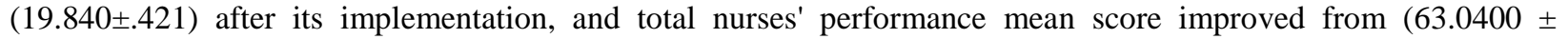
$7.94101)$ before implementation of educational program to (97.9200 .39590$)$ after its implementation. There was good improvement with highly significant difference $(\mathrm{p}<0.001)$ related to knowledge and practice of educational program. Conclusion: Majority of nurses had a satisfactory level of knowledge and practice toward oxygen therapy after applying educational program. Recommendations: Provide in-service education and training program for nurses regarding oxygen therapy.
\end{abstract}

\section{Key words: Educational Program \& Oxygen Therapy, Knowledge, Practice.}

\section{Introduction}

Oxygen $\left(\mathrm{O}_{2}\right)$ is life essential but as a drug has a maximum positive biological benefit and accompanying toxicity effects. Oxygen is therapeutic for treatment of hypoxemia and hypoxia associated with many pathological processes. When administering supplemental oxygen to treat hypoxemia associated with acute and chronic conditions, $\mathrm{O}_{2}$ toxicity by overexposure may be present. ( Payen et al., 2019).

Although $\mathrm{O}_{2}$ therapy has been used in the care of critically ill patients for many years. Though, regardless of the setting in which oxygen is delivered, it should be regarded as a drug. Its potency in treating hypoxemia is often underestimated and, if given inappropriately, it can be lethal. Patients must receive this therapy in an appropriate, safe and comfortable way. This depends on a sound understanding of why oxygen is being delivered, the methods of $\mathrm{O}_{2}$ delivery and the nursing needs of the patient receiving it. Therefore, the aim of this study was to assess knowledge and practice of nurses regarding oxygen therapy. (Nievas et al., 2019).

The most detrimental effect of breathing high concentration of $\mathrm{O}_{2}$ is the development of $\mathrm{O}_{2}$ toxicity. It can occur in any patient who breaths $\mathrm{O}_{2}$ concentrations of greater than $50 \%$ for longer than 24 hours. (Morton \& Fontaine 2018)
The central nervous system, respiratory system especially lungs, and eyes are the systems primarily affected. Hyperbaric $\mathrm{O}_{2}$ therapy patients, patients exposed to prolonged high levels of $\mathrm{O}_{2}$, infants, particularly the premature, and underwater divers are at particular risk for $\mathrm{O}_{2}$ toxicity. (Camporesi, 2014) The need for supplemental $\mathrm{O}_{2}$ therapy should always take precedence over concern about toxic effects. Arterial blood gas and pulse oximetry monitoring should be assessed. Primary means of managing $\mathrm{O}_{2}$ toxicity is to prevent it. There is no therapy to reverse toxic pulmonary changes. (Thygesen et al., 2018).

The use of supplemental $\mathrm{O}_{2}$ by emergency nurses has important implications for patient outcomes, yet there is significant variability in $\mathrm{O}_{2}$ administration practices. (Nippers \& Sutton 2014).

The nurse routinely inspects the skin and mucous membranes of the mouth and nares for signs of breakdown. For patients with nasal cannula the nurse inspects the ears upper lips and nares. Further breakdown can be prevented by providing skin barriers or cushions and possibly changing to another type of device. The mask may cause some patients anxiety with feeling of suffocation and as with all devices the nurse should ensure the patient's comfort. (Flasch, \& Henningfeld, 2018). 


\section{Significant of study}

Oxygen therapy needs a special nursing care to improve patient outcome and prevent complication. In 2018 about 8380 patients entered the emergency department 6870 patients of them need $\mathrm{O}_{2}$ administration. It means that about $81.9 \%$ of patient in emergency unit receiving $\mathrm{O}_{2}$ therapy. The use of supplemental $\mathrm{O}_{2}$ by emergency nurses has important implications for patient outcomes so this study will improve nurses' knowledge to practice safely for such group of patient.

\section{Aim of the study}

-To investigate the effect of educational program about oxygen therapy on the nurses' knowledge and practice in the emergency unit through the following:

a) Assessment of the nurses' knowledge and practice before the implementation of educational program.

b) Design the program based on the previous assessment.

c) Implement and evaluate the effect of the program on the nurses' knowledge and practice.

Research Hypotheses

- There will be significant difference between posttest knowledge score and the pretest knowledge score following implementation of educational program.

- There will be significant difference between posttest practice score and the pretest practice score following implementation of educational program.

- A positive relation will exist between knowledge and practice score obtained by critical care nurses receiving educational program.

\section{Subjects \& Method}

\section{Research design}

A quasi experimental research design with one group pre-test post-test approach was used to evaluate the effectiveness of structured educational program for the present study.

\section{Study variable}

-The independent variable is the educational program.

-The dependent variable is the nurses' knowledge and nurses' practice about oxygen toxicity.

\section{Setting}

The study was carried out at emergency unit in pediatric hospital at Assuit university hospital.

\section{Sample}

A convenient sample of 50 nurses was recruited from emergency unit in pediatric hospital at Assuit university hospital.

Tools of the study

Two tools were used in this study
Tool(1): (structure interview questionnaire)

This tool was developed by the researcher after review related literature to assess nurses' knowledge related to oxygen toxicity, this tool consisted of two part

Part 1: demographic data: It was concerned with demographic characteristic include questions about, nurses' code, age, sex, work place, years of experience, qualification and their attendance of related course training program about oxygen toxicity. It was included $\{6\}$ multiple choice question.

Part 2: knowledge assessment test (leung et al., 2016, Mahmoud et al., 2016, Adipa et al., 2015) It was conducted to assess the need for educational program and to evaluate it. It consisted of seven multiple choice questions, three true or false questions and four essay questions that cover the following areas: anatomy and physiology of respiratory system, oxygen concentration and uses, methods of oxygen delivery, Oxygen humidification, Oxygen complications, Manifestation of oxygen toxicity, Oxygen monitoring, patient health education, and nurse role in oxygenation.

Scoring system of nurses' knowledge: Two levels of scoring for questions were as the following:

Correct answer scored one, don't know or incorrect answer scored zero. The total scoring system of nurses' knowledge was 20 and it was categorized into two levels:

-satisfactory total score $\geq 60 \%$ of the total score. -unsatisfactory of total score $<60 \%$ of the total score.

Tool (2):Nurses' practice observational check list (lynn 2015, Taylor et al., 2015)

It was used before and after the implementation of the educational program. It consisted of the following items:

1- Administering oxygen by nasal cannula. It was included twelve steps.

2- Administering oxygen by mask. It was included elven steps.

3- Administering oxygen by tent. It was included fourteen steps.

4- Monitoring oxygen saturation by pulse oximetry. It was included twelve steps.

Scoring system of nurses' performance was as the following

- done step correctly scored (one point), done step incorrectly or not done scored (zero point). The total scoring system of the nurses' performance was 98 and it was categorized into two levels :

- satisfactory total score $\geq 60 \%$ of the total score.

- unsatisfactory of total score $<60 \%$ of the total score. 


\section{Method of data collection}

An individual interview was used to collect data the time needed to complete the tool was 15 minutes. Every nurse was interviewed at break time to collect data through (structure interview questionnaire).

\section{Observational check list}

Every nurse was observed to collect data of observational check list, observation checklist for nurses carried out during the morning shift two days /week and the time of each session was about two hours.

\section{Technique for data collection}

The study was conducted throughout three main phases which include: preparatory phase, implementation phase and evaluation phase.

\section{Preparatory phase}

- Permission to conduct the study obtained from the hospital responsible authorities, after explaining the aim and nature of the study.

- The data collection tools were developed by the researcher based on the relevant literature reviewing.

- The developed tools were tested for content validity by 7 experts in the field of the study and the necessary modifications were done.

- A pilot study was carried out on $10 \%$ (5 nurses) from sample using the study tool in order to check its applicability and understanding. Those included in the pilot study were included in the total sample if there were not major modification present.

- The reliability was tested for tool one (knowledge assessment tool) and was $0.88 \%$ and tool two (practice assessment tool) was $0.82 \%$ by using Cronbach's alpha which were accepted.

\section{Ethical consideration}

1- Research proposal was approved from Ethical

Committee in the Faculty of Nursing.

2- There was no risk for study subjects during application of the research.

3 - The study followed common ethical principles in clinical research.

4- Written consent was obtained from nurses that were willing to participate in the study, after explaining the nature and purpose of the study.

5-Nurses were assured that the data of this research will be used only for the purpose of research.

6- Confidentiality and anonymity was assured.

7- Nurses had the right to refuse to participate and or withdraw from the study without any rational any time.

\section{Ethical approval:}

An official authorization to conduct the study was obtained by the researcher from Assuit pediatric hospital responsible authorities. Oral consent for voluntary participation was obtained from each nurse and the nature and purpose of the study was described. The researcher emphasized that the participation is voluntary, confidentiality and anonymity of the subjects was assured through coding of all data.

Phase two :( Implementation phase)

Assessment of knowledge was done twice as follows:

- One at the beginning of the study was consider as pretest assessment.

-The second administration of questionnaire was carried out after implementation of educational program to identify its effect on nurses' knowledge.

Assessment of nurses' practice:

-The researcher observed the nurses' practice using observational check list tool before and immediately after implementation of educational program.

-The researcher completed the check list while the nurses demonstrate nursing procedure related to $\mathrm{O}_{2}$ delivery and monitoring.

\section{Construction of educational program}

_The educational program was developed by the researcher based on the previous assessment of the nurses' knowledge and practice about oxygen therapy.

_Teaching booklet was revised and modified based on the expertise comments. It was written in Arabic using simple language with illustration.

\section{Implementation of the program}

_The program was implemented in nurses' room in the emergency unit in pediatric hospital. Nurses divided into groups according to work status.

- Sessions arranged to take place when nurses working during morning shift in an attempt to maximize attendance.

- The nurses were divided in to 5 subgroup and each group contains 10 nurse, they were met two days/week.

- 4 educational sessions were implemented in addition to the preliminary one and time for each session about two hours.

_different methods were used as video, group discussion, power point for theoretical part, demonstration and re-demonstration for the practical part.

_A booklet was given to each nurse during session.

General objectives of the program

The overall objectives of the developed educational program was improving the nurses knowledge and practice about oxygen therapy.

Specific objectives of the program

By the end of the program the nurses will be able to:-

1) Describe the anatomy of the respiratory system.

2) Enumerate function of respiratory system.

3) Define oxygen and oxygenation.

4) List indications of oxygenation.

5) List oxygen delivery methods.

6) Enumerate oxygen humidification. 
7) List oxygen complication.

8) Define Oxygen toxicity.

9) Describe manifestation of oxygen toxicity.

10) Define Oxygen monitoring.

11) Describe Oxygen use in home.

12) Patient health education.

13) Nurse role in oxygenation and in oxygen toxicity.

Preliminary session (1)

In this session the researcher met the participant and explained the objectives and the content of the program, methods of evaluation of the program and the anatomy and physiology of respiratory system.

\section{Session (2) include}

Define oxygen, needs for oxygen, methods of the delivery, oxygen humidification, oxygen complication.

Session (3) include

Oxygen toxicity, manifestation, oxygen monitoring, oxygen receiving at home.

\section{Session (4) include}

Patient health education, nurse role in oxygenation and in oxygen toxicity.

Session (5) include
Implementation of oxygen delivery by nasal, mask, tent and using pulse oximeter

- In the last session the researcher summarized and emphasized the important point.

_ Each nurse demonstrates and re-demonstrates the steps individually and completely performed the steps.

\section{Evaluation phase}

The evaluation was done by the investigator twice by using tool $1 \& 2$ before (pre test) and immediately after (post test) implementation of educational program. This was done to evaluate the effect of the program on gaining nurses' knowledge and practice toward oxygen toxicity.

\section{Statistical analysis}

- Statistical analysis was performed using the software program package SPSS, version 20.

_ Data of obtained result were tabulated in the form of frequency using mean $\pm \mathrm{SD}$, number and percentage.

_ Using chi-square test to determine significant between variable.

_ Using t-test to compare significant.

\section{Results}

Table (1): distribution of demographic data among nurses under study ( $n=50$ )

\begin{tabular}{|l|c|c|}
\hline \multicolumn{1}{|c|}{ Age Mean \pm SD } & \multicolumn{2}{c|}{$27.94 \pm 4.683$} \\
\hline Variables & N & \% \\
\hline Sex & 2 & 4.0 \\
\hline - Male & 48 & 96.0 \\
\hline - Female & 21 & 42.0 \\
\hline $\begin{array}{l}\text { Level of education } \\
- \text { diploma }\end{array}$ & 16 & 32.0 \\
\hline - institute of nursing & 11 & 22.0 \\
\hline - bachelors & 2 & 4.0 \\
\hline - institute of technical health & 9 & 18.0 \\
\hline $\begin{array}{l}\text { Years of experience } \\
<1\end{array}$ & 3 & 6.0 \\
\hline $1-<5$ years & 21 & 42.0 \\
\hline $5-<10$ years & 17 & 34.0 \\
\hline$>10$ & 0 & 0.0 \\
\hline $\begin{array}{l}\text { Attendance of previous Training regarding oxygen toxicity } \\
- \text { Yes }\end{array}$ & 50 & 100 \\
\hline- No & & \\
\hline
\end{tabular}

Data described as $(n \& \%)$ chi-square and $( \pm S D)$ independent sample t-test 
Table (2): Comparison between nurses' knowledge mean scores pre and post implementing of educational program about oxygen therapy. $\mathrm{N}=50$

\begin{tabular}{|l|c|c|c|c|}
\hline \multicolumn{1}{|c|}{ Nurses knowledge } & \multirow{2}{*}{ Total score } & pretest & posttest & \multirow{2}{*}{ p. v } \\
\cline { 3 - 5 } & & Means \pm SD & Means \pm SD & \\
\hline Anatomy and physiology of respiratory tract & 2 & $.780 \pm .789$ & $2.00 \pm 0.00$ & $0.001^{* *}$ \\
\hline Indications that requires oxygen & 1 & $.92 \pm .274$ & $1.00 \pm 0.00$ & $0.042^{*}$ \\
\hline Oxygen toxicity & 4 & $1.480 \pm 809$ & $4.000 \pm 0.00$ & $0.001^{* *}$ \\
\hline Nursing precautions & 2 & $1.040 \pm 879$ & $1.900 \pm 303$ & $0.001 * *$ \\
\hline Nursing care for patient receiving oxygen & 6 & $4.266 \pm .703$ & $5.960 \pm .282$ & $0.001 * *$ \\
\hline $\begin{array}{l}\text { The complications resulting from the incorrect use of } \\
\text { oxygen }\end{array}$ & 1 & $.320 \pm .471$ & $.980 \pm .141$ & $0.001 * *$ \\
\hline Total knowledge mean score & 20 & $9.080 \pm 4.818$ & $19.840 \pm .421$ & $0.001^{* *}$ \\
\hline
\end{tabular}

Independent $t$-test $\quad *=$ Significant difference $* p \leq 0.05$

significant difference $P>0.05$

\section{Total nurses knowledge}

- Pre-test $\square$ posttest

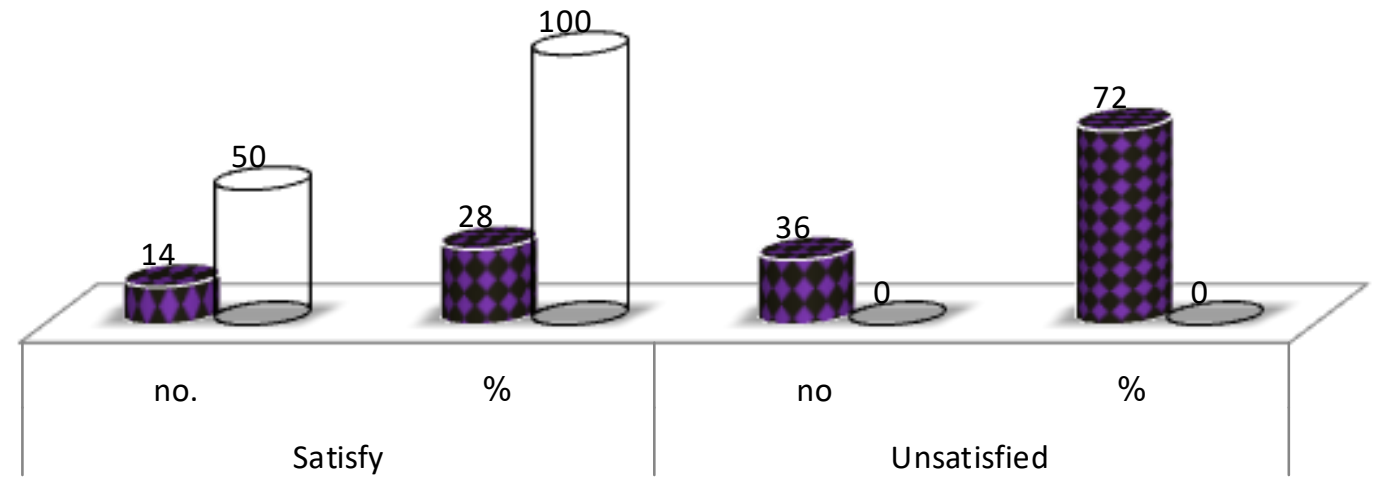

Figure(1):level of satisfaction among Nurses' knowledge score pre and post implementing of educational program about oxygen therapy. $\mathrm{N}=\mathbf{5 0}$.

Table (3): means distribution of total nurses' practice mean scores before and after implementation of educational program.

\begin{tabular}{|c|c|c|c|c|}
\hline \multirow{2}{*}{ followup } & \multirow{2}{*}{ Total score } & pretest & posttest & \multirow{2}{*}{ p.v } \\
\hline & & Mean \pm SD & Mean \pm SD & \\
\hline \multirow{2}{*}{ Nasal } & \multirow{2}{*}{24} & $16.0800 \pm 1.84988$ & $23.9600 \pm .19795$ & \multirow{2}{*}{0.001} \\
\hline & & & & \\
\hline \multirow{2}{*}{ Mask } & \multirow{2}{*}{22} & $14.4400 \pm 2.11081$ & $22.0000 \pm$ & \multirow{2}{*}{0.001} \\
\hline & & & .00000 & \\
\hline \multirow{2}{*}{ Pulse oximetry } & \multirow{2}{*}{24} & $14.6200 \pm 2.94778$ & $23.9600 \pm$ & \multirow{2}{*}{0.001} \\
\hline & & & .19795 & \\
\hline \multirow{2}{*}{ Tent } & \multirow{2}{*}{28} & $17.8600 \pm 2.19471$ & $28.0000 \pm$ & \multirow{2}{*}{0.001} \\
\hline & & & .00000 & \\
\hline \multirow{2}{*}{$\begin{array}{l}\text { Total practice } \\
\text { mean score }\end{array}$} & \multirow{2}{*}{98} & $63.0400 \pm 7.94101$ & $97.9200 \pm$ & \multirow{2}{*}{0.001} \\
\hline & & & .39590 & \\
\hline
\end{tabular}




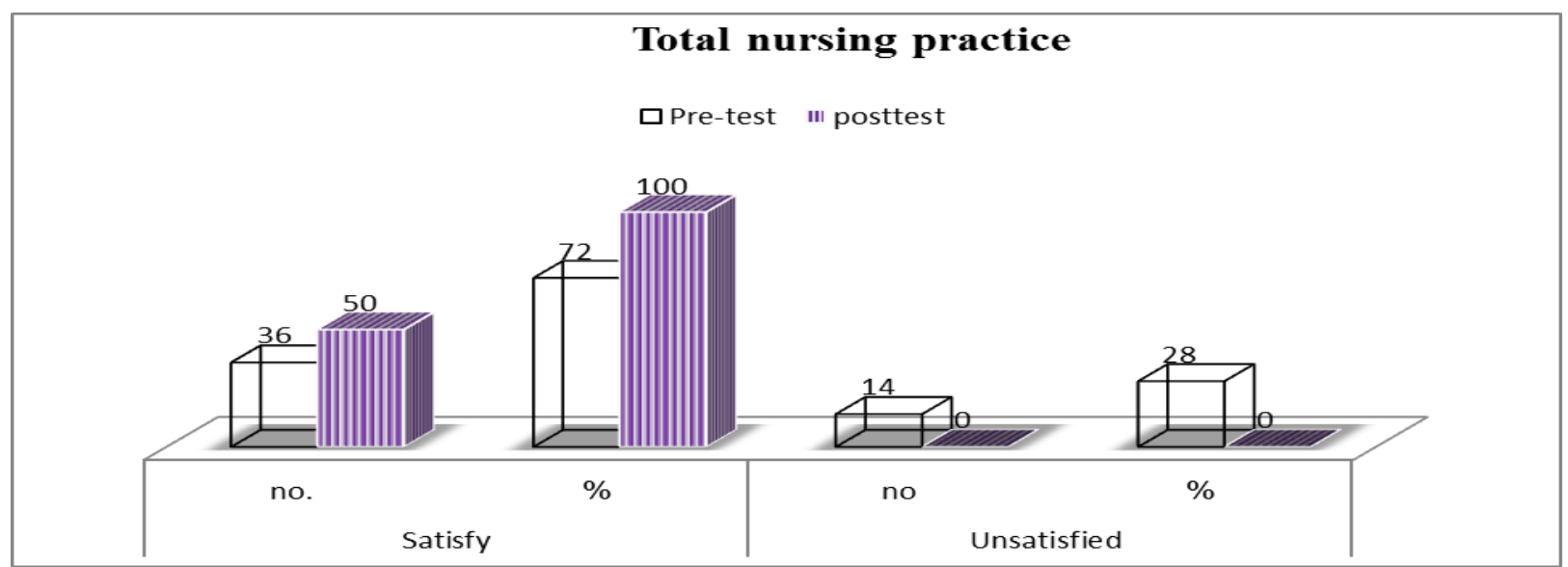

Figure (2): level of satisfaction among Nurses' practice mean score pre and post implementing of educational program about oxygen toxicity. $\mathrm{N}=50$

Table (4): Relation between total nurses' knowledge mean score pre-post test, and demographic characteristics $\mathbf{n}=\mathbf{5 0}$.

\begin{tabular}{|c|c|c|c|c|c|c|}
\hline \multirow{2}{*}{\multicolumn{2}{|c|}{ Variables }} & \multirow{2}{*}{$\mathbf{N}$} & \multirow{2}{*}{$\begin{array}{c}\text { Pretest } \\
\text { Mean } \pm \text { SD }\end{array}$} & \multirow{2}{*}{$\begin{array}{c}\text { Posttest } \\
\text { Mean } \pm \text { SD }\end{array}$} & \multirow{2}{*}{$\mathbf{P 1}$} & \multirow{2}{*}{$\mathbf{P 2}$} \\
\hline & & & & & & \\
\hline \multirow{5}{*}{$\begin{array}{ll}\text { Level of } \\
\text { education }\end{array}$} & Diploma & 21 & $8.523 \pm 4.884$ & $18.904 \pm .300$ & Ns & $* *$ \\
\hline & $\begin{array}{l}\text { institute } \\
\text { nursing }\end{array}$ & 16 & $7.687 \pm 5.147$ & $19.000 \pm 0.00$ & Ns & $* *$ \\
\hline & Bachelors & 11 & $12.272 \pm 2.969$ & $18.636 \pm .504$ & Ns & $* *$ \\
\hline & $\begin{array}{l}\text { institute of } \\
\text { technical health }\end{array}$ & 2 & $8.500 \pm 4.949$ & $18.000 \pm 1.414$ & Ns & $* *$ \\
\hline & Total & 50 & $9.080 \pm 4.818$ & $18.840 \pm .421$ & 0.086 & 0.002 \\
\hline \multirow{4}{*}{$\begin{array}{l}\text { Years of } \\
\text { experience }\end{array}$} & $<1$ & 9 & $7.333 \pm 5.567$ & $18.777 \pm .666$ & $\mathrm{Ns}$ & Ns \\
\hline & $1-<5$ years & 3 & $7.333 \pm 6.658$ & $18.666 \pm .577$ & Ns & Ns \\
\hline & $5-<10$ years & 21 & $9.571 \pm 4.566$ & $18.857 \pm .358$ & Ns & Ns \\
\hline & $>10$ years & 17 & $9.705 \pm 4.579$ & $18.882 \pm .332$ & $\mathrm{Ns}$ & Ns \\
\hline \multirow[t]{2}{*}{$\operatorname{sex}$} & Male & 2 & $11.00 \pm 1.41$ & $18.50 \pm .707$ & $\mathrm{Ns}$ & Ns \\
\hline & Female & 48 & $9.00 \pm 4.89$ & $18.85 \pm .412$ & 0.571 & .249 \\
\hline \multirow[t]{4}{*}{ Age group } & $20<30$ yrs.' & 40 & $8.47 \pm 4.87$ & $18.84 \pm 0.41$ & $\mathrm{Ns}$ & Ns \\
\hline & $30<40$ yrs & 9 & $11.66 \pm 4.12$ & $19.00 \pm 0.00$ & $\mathrm{Ns}$ & $\mathrm{Ns}$ \\
\hline & $>40$ yrs & 1 & $10.00 \pm 0.0$ & $18.00 \pm 0.00$ & $\mathrm{Ns}$ & Ns \\
\hline & & 50 & $9.08 \pm 4.81$ & $18.84 \pm 0.42$ & .198 & .109 \\
\hline
\end{tabular}


Table (5): Relation between nurses' practice mean scores pre-post test and demographic characteristics $\mathbf{n = 5 0}$.

\begin{tabular}{|c|c|c|c|c|c|c|}
\hline \multirow{2}{*}{\multicolumn{2}{|c|}{ Variables }} & \multirow{2}{*}{$\mathbf{N}$} & \multirow{2}{*}{$\begin{array}{c}\text { Pretest } \\
\text { Mean } \pm \text { SD }\end{array}$} & \multirow{2}{*}{$\begin{array}{c}\text { posttest } \\
\text { Mean } \pm \text { SD }\end{array}$} & \multirow{2}{*}{ P1 } & \multirow{2}{*}{2} \\
\hline & & & & & & \\
\hline \multirow[t]{5}{*}{ Level of education } & Diploma & 21 & $63.857 \pm 7.863$ & $97.904 \pm .436$ & Ns & Ns \\
\hline & $\begin{array}{c}\text { institute of } \\
\text { nursing }\end{array}$ & 16 & $61.812 \pm 7.704$ & $97.875 \pm .500$ & Ns & Ns \\
\hline & Bachelors & 11 & $63.909 \pm 9.417$ & $98.000 \pm 0.00$ & Ns & Ns \\
\hline & $\begin{array}{c}\text { institute of } \\
\text { technical health }\end{array}$ & 2 & $59.500 \pm 2.121$ & $98.000 \pm 0.00$ & Ns & Ns \\
\hline & Total & 50 & $63.040 \pm 7.941$ & $97.920 \pm .395$ & 0.780 & 0.865 \\
\hline \multirow[t]{5}{*}{ Years of experience } & $<1$ & 9 & $58.777 \pm 5.494$ & $97.777 \pm .666$ & Ns & Ns \\
\hline & $1-<5$ years & 3 & $59.333 \pm 5.033$ & $98.000 \pm .000$ & Ns & Ns \\
\hline & $5-<10$ years & 21 & $62.952 \pm 7.473$ & $97.904 \pm .436$ & Ns & Ns \\
\hline & $>10$ years & 17 & $66.058 \pm 9.086$ & $98.000 \pm .000$ & Ns & Ns \\
\hline & Total & 50 & $63.040 \pm 7.941$ & $97.920 \pm .395$ & 0.124 & 0.584 \\
\hline \multirow{2}{*}{ Sex } & Male & 2 & $60.00 \pm 1.14$ & $98.00 \pm 0.00$ & Ns & Ns \\
\hline & Female & 48 & $63.16 \pm 8.08$ & $97.91 \pm 0.403$ & 0.85 & 0.77 \\
\hline \multirow{4}{*}{ Age group } & $20<30 \mathrm{yrs}$ & 40 & $62.45 \pm 6.95$ & $97.91 \pm 0.41$ & Ns & Ns \\
\hline & $30<40 \mathrm{yrs}$ & 9 & $65.11 \pm 11.87$ & $98.00 \pm 0.00$ & Ns & Ns \\
\hline & $>40 \mathrm{yrs}$ & 1 & $68.00 \pm 0.00$ & $98.00 \pm 0.00$ & $\mathrm{Ns}$ & Ns \\
\hline & Total & 50 & $63.04 \pm 1.12$ & $97.92 \pm 0.39$ & 0.552 & .918 \\
\hline
\end{tabular}

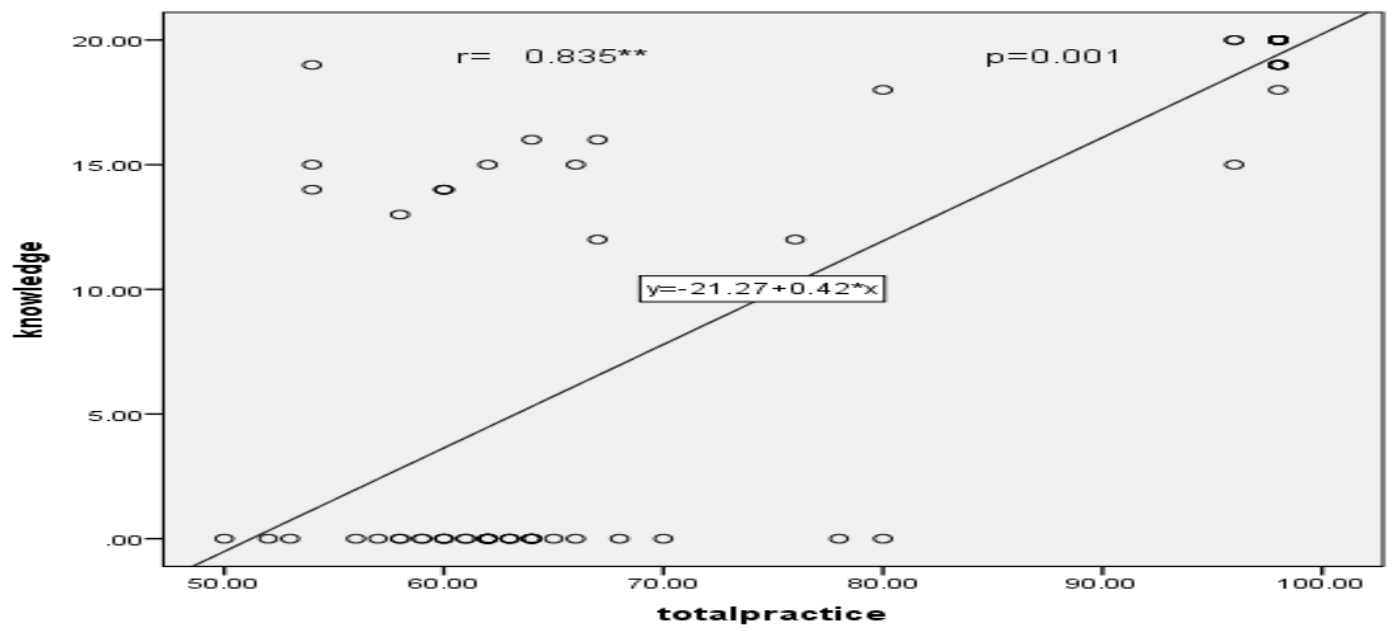

Figure (3): Relation between total nurses' knowledge and practice after implementation of educational program.

Table (1): Shows that the mean age of the nurses was 27.9 and $(96 \%)$ of nurses are females. Concerning their educational level (42\%) of nurses held 3 years nursing diploma, $(32 \%)$ held technical institute of nursing, (22\%) held Bachelor of nursing and (4\%)held technical health institute of nursing. Moreover (42\%)of nurses had work experience less than 10 years ,(34\%)had more than 10 years ,(18\%)had less than 1 year and $(6 \%)$ had more than 5years. In relation to their previous training about oxygen toxicity this table reveals that $(98 \%)$ of them did not receive any training.
Table (2): Shows that there is a highly significance differences in nurses knowledge mean score between pre and post implementation of teaching program regarding oxygen therapy $(\mathrm{p}<0.001)$. Figure (1): Illustrates that about $72 \%$ of nurses have unsatisfied knowledge in the pretest and $100 \%$ of nurses have a satisfied knowledge in posttest with highly significance difference between them. Table (3): Illustrates that there is a highly significance differences in nurses practice mean scores in comparison between pre and post 
implementation of teaching program as regard of oxygen therapy $(\mathrm{p}<0.001)$.

Figure (2): Illustrates that about $14 \%$ of nurses have unsatisfied practice in pretest and $100 \%$ of nurses have a satisfied practice after implementation of educational program.

Table (4): Illustrates there is significant relation between total nurses' knowledge mean score and level of education after implementation of teaching program $(p<0.05)$ and there is no significant relation between nurses' knowledge, years of experience, sex and age at pre and post implementation of educational $\operatorname{program}(\mathrm{p}>0.05)$.

Table (5): Illustrates that there was no statistical significant relation between nurses' practice mean score (pre and posttest) and their demographic characteristics $(\mathrm{p}>0.05)$.

Figure (3): Illustrates that there is highly statistically positive correlation between total nurse' knowledge and total practice after implementation of educational program $(\mathrm{p}<0.001)$

\section{Discussion}

Oxygen therapy is the administration of $\mathrm{O}_{2}$ as a medical intervention, which can be for a variety of medical conditions. Assessment of need for $\mathrm{O}_{2}$ in most instances is a nursing responsibility. Critical care nurses frequently and independently manage $\mathrm{O}_{2}$ therapy. Despite the importance of the $\mathrm{O}_{2}$ therapy, there is limited evidence to inform or support critical care nurses' $\mathrm{O}_{2}$ therapy practices. (Chou et al., 2016). The study result revealed that majority of the nurses were females, and bachelor of nursing degree. In my opinion most of them was females because that the nursing schools and faculty of nursing newly inserted the male students in their study. And most of them hold bachelor of nursing degree because they were more qualified to work in emergency department. The number of years of emergency nursing experience was from 5 to 10 years of experience. This result is in congruent with Eastwood et al., (2012) who reported that the majority of nurses who are working in ICU generally had bachelor degree in nursing.

In relation to attending any previous training program, the nurses had not attending any previous training. This might due to hospital have not staff development program related to $\mathrm{O}_{2}$ toxicity. This result was supported by Rochester (2017) who said that nurses who are working in the intensive care unit needs additional education to provide optimal care for patients who receive $\mathrm{O}_{2}$ therapy to prevent $\mathrm{O}_{2}$ toxicity. In addition to Chen et al., (2018) mentioned that in their study participants from nurses had never attended training courses on oxygen therapy.
Participants' average age was 40 years $(\mathrm{SD}=4.68)$. It may be due to the administrators selected older age nurses to be able to perform mainly tasks in the intensive care unit effectively. This result was in the same line with Considine et al., (2006).

Regarding to nurses' knowledge mean score about $\mathrm{O}_{2}$ therapy for such group of nurses, the study results revealed that there were significant improvement intervention of educational program with a highly statistical difference with $\mathrm{p}$ value (0.001). This because that the educational program had positive effect which reflect their need for educational program related to $\mathrm{O}_{2}$ therapy. And Low level of nurses' knowledge before implementation of educational program may be attributed to the fact that this part not included in nursing curricula which affects level of nurses knowledge.

These results were in the similar line with Markocic et al., (2016) who mentioned the nurses must be educated about management and specific needs of patients receiving oxygen to improve their skill and prevent expected complications (oxygen toxicity).

In addition to Aloushan et al., (2019) who declared that the poor knowledge in using oxygen therapy (OT) in those critical situations could deteriorate patients' condition and outcome. Therefore, nurses need further education about the risk of administering $\mathrm{O}_{2}$ therapy to patients.

Also Urden et al., (2016) mentioned that nurses' knowledge toward oxygen therapy is moderate and they recommended the need for in-service educational programs to develop nurses' knowledge and practice in order to fit this contemporary trend in health care.

In addition to Hagos et al., (2017) who indicated that although there was a high level of awareness towards $\mathrm{O}_{2}$ therapy among medical students, but there was a poor level of general knowledge about $\mathrm{O}_{2}$ therapy and toxicity. According to Wang et al., (2017) revealed that during pre-test $40 \%$ from nurses had inadequate knowledge regarding $\mathrm{O}_{2}$ therapy. After intervention showed that $80 \%(\mathrm{p}<0.05)$ was gained knowledge.

The total nurses' practice mean score before implementation of educational program was unsatisfactory in the current study. It may be due to, the lack in the nurses efficiency of updating their practice after being and settled in the clinical environment for a longer time and possible explanation for this finding is that the workload. (Vargas et al., 2015)

Generally nurses' performance mean score about $\mathrm{O}_{2}$ administration, the results showed that there were highly significant improvements in the nurses' practice regarding methods of oxygen therapy after implementation of educational program. 
There was an improvement of nurses' total performance mean scores regarding administering $\mathrm{O}_{2}$ by nasal cannula, mask and tent in addition to pulse oximetry procedure. It is because that educational programs for nursing staff play an important role in developing and enhancing their skills needed to provide high standards of care to their patients.

This is in concordance with Hernández et al., (2016) who found in their research that; majority of the nurses which represents $(88 \%)$ had proper practice regarding administrating $\mathrm{O}_{2}$ by nasal cannula, and (82\%) had Proper performance regarding administrating $\mathrm{O}_{2}$ by face mask these might be due to nurses had good practice about $\mathrm{O}_{2}$ therapy. The study result revealed that there was highly statistical significant relation between nurses' knowledge mean score and their educational level after implementation of educational program, with $\mathrm{P}$. value $=0.002$. It may be because that the content of educational program was included in their curriculum.

The study found that there was no statistical significant relation between nurses' practice mean score (pre and posttest) and their demographic characteristics either their level of education and years of experience. This result may be due to the studied nurses were homogenous group; the majority of the nurses nearly at the same age and the same years of experience and nurses gain their practice from the field.

The result of this study does not agree with Mohsen et al., (2016) who reported that the level of performance of the nurses with baccalaureate degree is higher than the level of secondary school degree nurses.

Finally, the findings of the present study supported the research hypothesis that nurses working emergency unit who are exposed to educational program about $\mathrm{O}_{2}$ toxicity care showed high score of practice after test (posttest) than that before (pretest).

\section{Conclusion}

Based on the results of this study, it could be concluded that: The majority of nurses had a satisfactory knowledge and practice toward oxygen toxicity after applying educational program. It was statistical significant relation between total nurses' knowledge and their practice post educational program.

\section{Recommendation}

_ Provide in-service education and training program for critical care nurses regarding oxygen toxicity should be available in a written format in critical units and all units.
_ Regular assessment of nurses' knowledge and practices by the trainer who responsible for annual training program.

\section{References}

1. Adipa, F., Aziato, L., \& Zakariah, A., (2015): Qualitative exploration of nurses' perspectives on clinical oxygen administration in Ghana. International Journal of Africa Nursing Sciences, 2, 42-46.

2. Aloushan, A., Almoaiqel, F., Alghamdi, R. N., Alnahari, F., Aldosari, A., Masud, N., \& Aljerian, N., (2019): Assessment of knowledge, attitude and practice regarding oxygen therapy at emergency departments in Riyadh in: A cross-sectional study. World journal of emergency medicine, 10(2), 88.

3. Camporesi E., (2014): Side effects of hyperbaric oxygen therapy, PubMed, 41(3):253

4. Carol Taylor, Carol Lillis, Pamela lynn, Priscilla Lemone, (2015): Fundamentals of Nursing , 8th edi, wolters Kluwer, china ,p1449:1453

5. Chen, Y., Niu, M., Zhang, X., Qian, H., Xie, A., \& Wang, X., (2018): Effects of home-based lower limb resistance training on muscle strength and functional status in stable Chronic obstructive pulmonary disease patients. Journal of clinical nursing, 27(5-6), e1022-e1037.

6. Chou, R., Gordon, D., de Leon-Casasola, O., Rosenberg, J., Bickler, S., Brennan, T., \& Griffith, S., (2016): Management of Postoperative Pain: a clinical practice guideline from the American pain society, the American Society of Regional Anesthesia and Pain Medicine, and the American Society of Anesthesiologists' committee on regional anesthesia, executive committee, and administrative council. The Journal of Pain, 17(2), 131-157.

7. Considine, J., Botti, M., \& Thomas, S., (2006): The effects of specific educational preparation on emergency nurses' clinical decisions regarding supplemental oxygen administration. Nursing \& health sciences, 8(2), 73-80.

8. Eastwood, G., Reade, M., Peck, L., Baldwin, I., Considine, J., \& Bellomo, R., (2012). Critical care nurses' opinion and self-reported practice of oxygen therapy: a survey. Australian Critical Care, 25(1), 23-30.

9. Flasch, E., Brueck, N., Lynn, J., \& Henningfeld, J., (2018): PULMONARY SYSTEM. AACN Core Curriculum for 
Pediatric High Acuity, Progressive, and Critical Care Nursing

10. Hagos, K., Zong, J., Li, D., Liu, C., \& Lu, X., (2017): Anaerobic co-digestion process for biogas production: Progress, challenges and perspectives. Renewable and Sustainable Energy Reviews, 76, 1485-1496.

11. Hernández, G., Vaquero, C., González, P., Subira, C., Frutos-Vivar, F., Rialp, G., \& Fernández, R., (2016): Effect of postextubation high-flow nasal cannula vs conventional oxygen therapy on reintubation in low-risk patients: a randomized clinical trial. Jama, 315(13), 13541361.

12. Leung, A., Nerenberg, K., Daskalopoulou, S., McBrien, K., Zarnke, K., Dasgupta, K., \& Bolli, P., (2016): Hypertension Canada's 2016 Canadian hypertension education program guidelines for blood pressure measurement, diagnosis, assessment of risk, prevention, and treatment of hypertension. Canadian Journal of Cardiology, 32(5), 569-588.

13. Mahmoud, A., Alseed, H., Abdallah, H., Awad, A., \& Elhussein, G., (2016): assessment of knowledge and practice of nurses regarding oxygen therapy in elmak nimir university hospital., European Journal of Pharmaceutical and Medical Research ,3(4), 30-35

14. Markocic, S., Humphries, M., Tarne, K., Watts, M., \& Collins, L., (2016): What are the risks and knowledge deficits for prescribing and administering opioids in the ward environment? A quality project on assessing and improving knowledge. Nurse education in practice, 17, 182-187.

15. Mohsen, M., Safaan, N., \& Okby, O., (2016): Nurses' Perceptions and Barriers for Adoption of Evidence Based Practice in Primary Care: Bridging the Gap. American Journal of Nursing Research, 4(2), 25-33.

16. Morton P., \& Fontaine D.,(2018): Critical Care Nursing (A Holistic Approach), 10 ${ }^{\text {th }}$ edi , Lippincott Williams, china ,p512.

17. Nievas, I., Fahy, A., Olson, M., \& Anand, K., (2019): Management of Status Asthmaticus in Critically Ill Children. In Pediatric Critical Care (pp. 63-81). Springer, Cham.

18. Nippers, I., \& Sutton, A., (2014): Oxygen therapy: professional compliance with national guidelines. British Journal of Nursing, 23(7), 382-386

19. Lynn, P., (2015), Skill Checklists for Taylor's Clinical Nursing Skills A NURSING PROCESS APPROACH, $4^{\text {th }}$ edi, wolters Kluwer, china, p(297\&301:303)
20. Payen, V., Zampieri, L., Porporato, P., \& Sonveaux, P., (2019): Pro-and antitumor effects of mitochondrial reactive oxygen species. Cancer and Metastasis Reviews, 1-15.

21. Rochester H., (2017): sevsenth report of joint national committee on prevention, detection, evaluation and treatment health care journal, 42(6), 1206_1252

22. Thygesen, $\bar{K}$., Alpert, J., Jaffe, A., Chaitman, B., Bax, J., Morrow, D., \& White, H., (2018): Fourth universal definition of myocardial infarction. Journal of the American College of Cardiology, 72(18), 2231-2264.

23. Urden D., Linda, Kathleen M., Stacy, Mary E., Lough, (2016): Priorities on Critical Care nursing, 7th edi ,Elsevier , Candap103\& p270\&p(301:303).

24. Vargas F., Saint-Leger M., Boyer A., (2015): Physiologic effects of high-flow nasal cannula oxygen in critical care subjects. Respir Care., 60(10):1369-76. doi:10.4187/respcare.03814

25. Wang, T., Tan, J., Xiao, L., \& Deng, R., (2017): Effectiveness of disease-specific selfmanagement education on health outcomes in patients with chronic obstructive pulmonary disease: an updated systematic review and metaanalysis. Patient education and counseling, 100(8), 1432-1446. 